\title{
ARTICLE Hispidulin induces ER stress-mediated apoptosis in human hepatocellular carcinoma cells in vitro and in vivo by activating AMPK signaling pathway
}

\author{
Mei Han ${ }^{1}$, Hui Gao ${ }^{1}$, Jing Xie ${ }^{2}$, Yin-ping Yuan ${ }^{3,4}$, Quan Yuan ${ }^{5}$, Ming-quan Gao ${ }^{1}$, Kai-li Liu ${ }^{1}$, Xue-hong Chen ${ }^{2}$, Yan-tao Ha. \\ Zhi-wu Han ${ }^{6}$
}

Hispidulin (4, 5,7-trihydroxy-6-methoxyflavone) is a phenolic flavonoid isolated from the medicinal pla it S. involuc, ia, which exhibits anti-neoplastic activity against several types of cancer. However, the mechanism underlying it. nti-cancer activity against hepatocellular carcinoma (HCC) has not been fully elucidated. In this study, we investigated whr or a. 'now nispidulin-induced apoptosis of human HCC cells in vitro and in vivo. We showed that hispidulin (10, $20 \mu \mathrm{mol} / \mathrm{I}$ / dos 'ependently inhibited cell growth and promoted apoptosis through mitochondrial apoptosis pathway in human HCC MMC772 $211 \mathrm{~s}$ and Huh7 cells. More importantly, we revealed that its pro-apoptotic effects depended on endoplasmic retic um ess (ERS) and unfolded protein

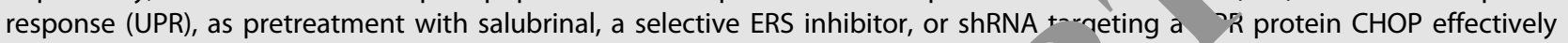
abrogated hispidulin-induced cell apoptosis. Furthermore, we showed that hispid ilin-ı duced apoptosis was mediated by activation of AMPK/mTOR signaling pathway as pretreatment with Compound C, ihibitor, or AMPK-targeting siRNA reversed the pro-apoptotic effect of hispidulin. In HCC xenograft nude mice, adminis ion of hispidulin $(25,50 \mathrm{mg} / \mathrm{kg}$ every day, ip, for 27 days) dose-dependently suppressed the tumor growth, accompar hv ind, cing ERS and apoptosis in tumor tissue. Taken together, our results demonstrate that hispidulin induces ERS-mediated ip iosis in HCC cells via activating the AMPK/ mTOR pathway. This study provides new insights into the anti-tumor activity of hispidulin in HCC.

Keywords: hispidulin; hepatocellular carcinoma; mitochondr: רpopt s; endoplasmic reticulum stress; CHOP; AMPK/mTOR; Z-LEHD-FMK; salubrinal; Compound C

Acta Pharmacologica Sinica (2019) 40:666-676; httpc $/ / / \mathrm{c}$

$038 / s 41401-018-0159-7$

\section{INTRODUCTION}

Hepatocellular carcinoma (HCC) is a major blic he: Ith problem worldwide, but it is especially problemat. hina due to hepatitis $B$ virus infection [1, 2]. Ep nological statistics show that $\sim 782,000$ newly diagnosed cases of $/$ and 745,000 deaths occurred worldwide in 2012 Surgic resection and traditional chemotherapy are typical + ratm nt opt ons for patients with HCC. However, the overall progh. ic. ents with HCC is poor, and only a minority of $\mathrm{H} C \mathrm{C}$ patien are eligible for surgical resection due to late stage ah osis [4]. One of the greatest obstacles in HCC treatment is the currence of multi-drug resistance in response to chemotherc eutic drugs, such as 5-FU [5] and sorafenib : 7]. 'ence, the discovery of new potential therapeutic targets and $h$. tmen strategies has been a research hotspot for HCC.

opt ic or programmed cell death, plays a crucial role in cont. "ny culular homeostasis and has been considered as a major $u$ at for chemotherapeutic agents to eradicate cancer cells [8]. The endoplasmic reticulum (ER), a eukaryotic organelle, is responsible for protein biosynthesis and folding and calcium storage regulation, and ER dysfunction may be triggered by a number of environmental, physiological, or pathological stimuli, such as oxidative stress, disordered calcium metabolism, elevated protein synthesis, and nutritional imbalance [9]. ER stress causes an accumulation of unfolded or misfolded proteins. In response to ER stress, cells activate UPR as an attempt to correct ER stress and restore normal function. Three ER transmembrane sensors, protein kinase RNA-like ER kinase (PERK), inositol-requiring 1a (IRE1a), and activating transcription factor- 6 (ATF6) from the binding immunoglobulin protein (BiP), comprise the three arms of UPR. However, under conditions of prolonged stress, UPR commits the cells to apoptosis [10]. Recently, accumulating studies have highlighted the critical role of ER in cancerous cell apoptosis [11]. Given the ability of prolonged or severe ER stress to initiate cell apoptosis via UPR [10], inducing ER stress has been considered as a novel mechanism for anti-cancer agents.

Natural products have been shown to provide health benefits to humans [12]. Hispidulin (4',5,7-trihydroxy-6-methoxyflavone, $\mathrm{C}_{16} \mathrm{H}_{12} \mathrm{O}_{6}$, molecular weight $300.3 \mathrm{~g} / \mathrm{mol}$ ) is a phenolic flavonoid isolated mainly from $\mathrm{S}$. involucrata, a medicinal plant traditionally

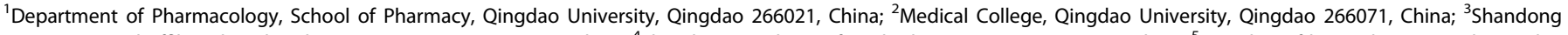

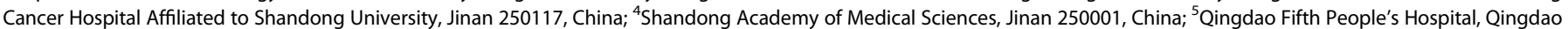
266000, China and ${ }^{6}$ The Affiliated Hospital of Qingdao University, Qingdao 266003, China

Correspondence: Hui Gao (huigao@qdu.edu.cn)

Received: 10 January 2018 Accepted: 4 July 2018

Published online: 14 September 2018 
used in oriental medicine [13]. In recent years, accumulating evidence has demonstrated the pleiotropic effects of hispidulin, including anti-inflammatory, antioxidant, anti-thrombotic, antiepileptic, neuroprotective, and anti-osteoporotic activities [14-19]. More importantly, many in vivo and in vitro studies have demonstrated that hispidulin exerts anti-tumor effects against a variety of solid tumors and hematological malignancies [20-22]. Previous studies also evidenced the anti-cancer activities of hispidulin in renal cell carcinoma, acute myeloid leukemia, gallbladder cancer, colorectal cancer, and hepatocellular carcinoma [23-28]. In the context of HCC, it has been identified that hispidulin exerts anti-proliferative and pro-apoptotic effects on HepG2 cells $[29,30]$. However, evidence that ERS and apoptosis are associated with the anti-cancer effect of hispidulin remains elusive in HCC.

In this paper, we report that the activation of ERS signaling by hispidulin at least partly contributed to its pro-apoptotic effect against HCC cells. Moreover, the pro-apoptotic effect of hispidulin is associated with mitochondrial apoptosis and modulation of the AMPK/mTOR signaling pathway.

\section{METHODS AND MATERIALS}

Cell culture and treatment

Human SMMC7721 and Huh7 cells were obtained from the Shanghai Cell Bank, China, and maintained in Dulbecco's Modified Eagle's Medium (DMEM) supplemented with $10 \%$ fetal bovine serum (Invitrogen, USA). Cells were grown at $37^{\circ} \mathrm{C}$ in a $5 \% \mathrm{CO}_{2}(\mathrm{v} /$ v) with humidified atmosphere.

Determination of cell viability

Cell viability was determined by Cell Counting Kit-8 (CCK-8, Beyotime, Shanghai, China). Briefly, cells were treated withdifferent concentrations of hispidulin for $24 \mathrm{~h}$ or $48 \mathrm{~h}$. Followi.y treatment, the optical density of viable cells was mear rec' at $450 \mathrm{~nm}$ in a spectrophotometer (Tecan Group Ltd, Männec

Switzerland). Cell viability assays were performed in triclicate.

Colony formation assay

Approximately $500 \mathrm{HCC}$ cells were plated in earn well of a st, well plate. Cultures were maintained for 14 days $w$ hout fresh medium feeding at $37{ }^{\circ} \mathrm{C}$ in a humidified atmosphere $59 \%$ ar and $5 \%$ $\mathrm{CO}_{2}$. Cells were fixed with $4 \%$ paraformald in or $15 \mathrm{~min}$, stained with crystal violet for $30 \mathrm{~min}$, a motographed using a digital camera (Nikon DXM-1200, Tokyo, Japa. Lell colonies with over 50 cells were counted lony ormation assays were performed in triplicate.

Hoechst 33258 stainind

Nuclear staining was $p$ ormed u, ing a Hoechst 33258 Staining Kit (Beyotime, China, Bric Hoechst $33258(2 \mu \mathrm{g} / \mathrm{mL}$, Beyotime, China) was added to coun ne total cells and dead cells. After incubation $\mathrm{fc} 20 \mathrm{l}$ in at $37^{\circ} \mathrm{C}$, the stained cells were examined using a fluoresc e mi roscope.

Flow tom trv anarysis of apoptosis

Cell ap osis was determined using a FITC Annexin V apoptosis kit (BD Ph, angen, Franklin Lakes, NJ, USA). Briefly, the cells were harvested at a density of $5 \times 10^{5}$ cells $/ \mathrm{mL}$ and incubated with Annexin V-FITC and propidium (PI) in the dark for $15 \mathrm{~min}$ before detection with flow cytometry (Beckman Coulter Inc, Miami, FL, USA). Flow cytometry analysis was performed in triplicate.

Measurement of mitochondrial membrane potential

Fluorochrome dye JC-1 was used to evaluate the changes in the mitochondrial membrane potential (MMP) as described previously [31]. Briefly, Huh7 or SMMC7721 cells were incubated with 10 or
$20 \mu \mathrm{M}$ hispidulin for $48 \mathrm{~h}$. Following incubation, the cells were stained with $\mathrm{JC}-1$ for $20 \mathrm{~min}$. Cells were then harvested and rinsed with JC-1 staining buffer $(1 \times)$ twice. The stained cells were imaged immediately at $\times 200$ using a fluorescence microscope (OLYMPUS, Japan).

\section{Caspase- 9 and caspase- 12 activity assay}

The activity of caspase- 9 and caspase- 12 was measured using an ELISA kit following the manufacturer's instructions (Abcam, Shanghai, China). The activity of caspase- 9 or caspac-12 was assessed by measuring the fluorescence intensity. All caspase activity assays were performed in triplicate.

Western blotting

Proteins were isolated from the control an hispidc in-treated cells as previously described [25]. Appronimat $40 \mathrm{ag}$ of total protein samples were electrophorese on SDS-PA $<$ before they were transferred to a PVDF membran The menibranes were then blocked with $5 \%(\mathrm{w} / \mathrm{v})$ non-fat nilk, shed with Tris-buffered saline-Tween solution (TBST), ana ubatcu overnight at $4{ }^{\circ} \mathrm{C}$ with primary antibodies according to th nanufacturer's instructions. The primary antibodies $a$. ct cleav $€ d$ caspase-3, cleaved PARP, cleaved caspase-9, cleaved pase-12, mitochondrial cyto $C$, cytosol cyto C, PUN HOP, G, 18, p-PERK, ATF4, p-elF2a, Bcl-2, Bax, p-AMPK, AN $\mathrm{TK}, \mathrm{f}$ mTOR, mTOR, and Ki-67 were purchased from Abcam (Sha. al, ala); $\beta$-actin and COX-IV were used as internal controls anc rehased from Beyotime (Shanghai, China). The seconc antibog es used in this study were goat anti-rabbit IgG-HRP an 1 .... Cuse IgG-HRP (Beyotime, Shanghai, China). After washin with TBST, a secondary antibody was added and in hated for $2 \mathrm{~h}$. The blots were washed, and the signal was dete d using a chemiluminescent substrate (KPL., Guildford, UK). andS n software (Glyko, Novato, CA) was used to quantify the density. All Western blotting assays were performed in trip cate.

Interference vector construction and transfection

The shRNA oligo nucleotide-targeting CHOP was synthesized according to a previously published sequence [32]. AMPK a1/ a2 siRNA was purchased from Santa Cruz (Santa Cruz, CA). Cells were cultured overnight and then transfected with shRNA (siRNA) or scramble shRNA (siRNA) using Lipofectamine 3000 (Invitrogen). At $48 \mathrm{~h}$ post transfection, the knockdown was verified by Western blot analysis.

\section{Xenograft model}

Eight-week-old male athymic BALB/c nu/nu mice were kept under pathogen-free conditions. Animal experiments for this study were approved by the Institutional Animal Care and Use Committee at Qingdao University. Huh7 cells $\left(1 \times 10^{7}\right.$ cells $\left./ \mathrm{mL}\right)$ were injected into the left flanks of the mice. Fifteen days after injection, the mice were randomly divided into three groups (eight mice per group) to receive intraperitoneal (IP) injections as follows: (A) vehicle $(0.9 \%$ sodium chloride and $1 \%$ DMSO), (B) hispidulin ( 25 $\mathrm{mg} / \mathrm{kg} /$ day for 27 days), and (C) hispidulin ( $50 \mathrm{mg} / \mathrm{kg} /$ day for 27 days). Mouse body weight and tumor volumes were measured every 3 days. IHC staining and TUNEL assay were performed on cryostat sections ( $4 \mu \mathrm{m} / \mathrm{section})$ of Huh7 cells xenograft tumors as described [33].

Statistical analysis

The data are presented as mean \pm SD (standard deviation) and represent the results of three separate experiments. Statistical comparisons between cell lines were analyzed by one-way ANOVA followed by Dunnett's $t$ test. Experimental data were analyzed by GraphPad Prism software (GraphPad Software Inc., La Jolla, CA). A $P<0.05$ was considered to be statistically significant, and a $P<0.01$ indicated notable statistical significance. 
a

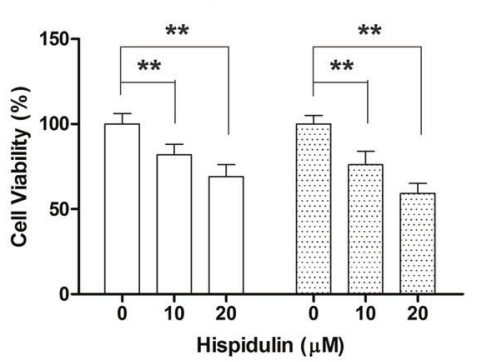

b

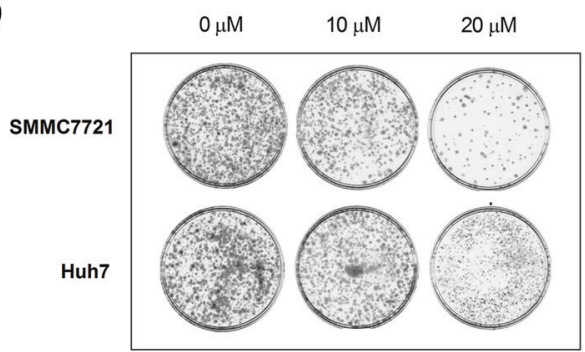

C

$0 \mu \mathrm{M}$

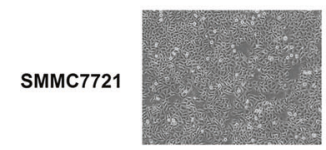

Huh7

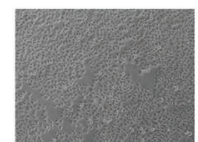

$\square$ 24-hour

5 48-hour
$10 \mu \mathrm{M}$

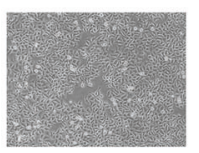

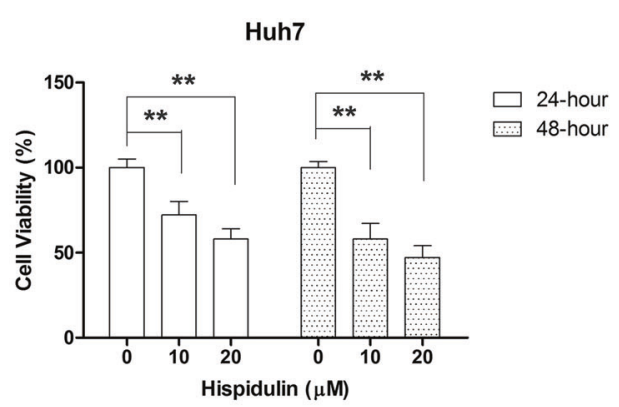

$20 \mu \mathrm{M}$

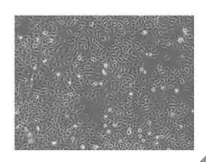

d
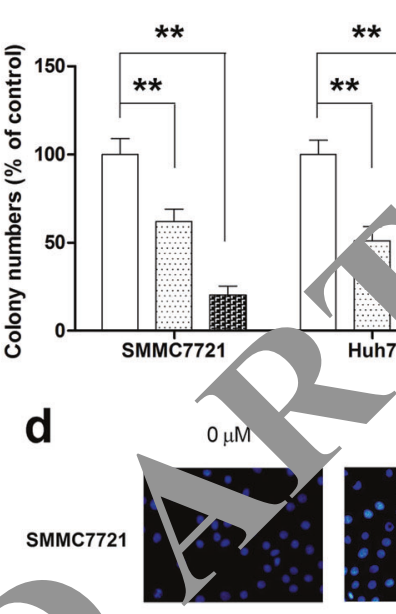

*

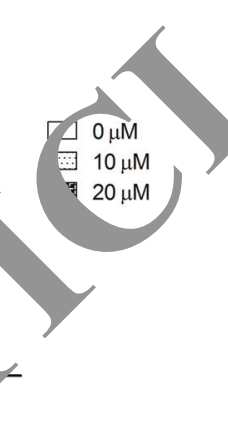

Huh7 )

$10 \mu \mathrm{M}$

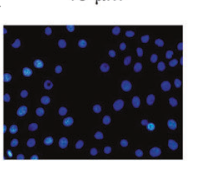

$20 \mu \mathrm{M}$
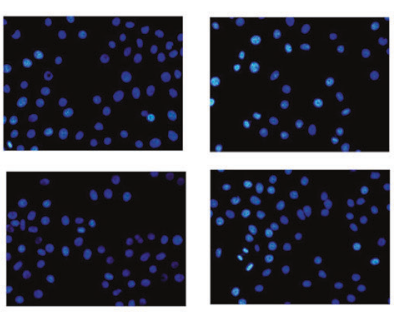

e
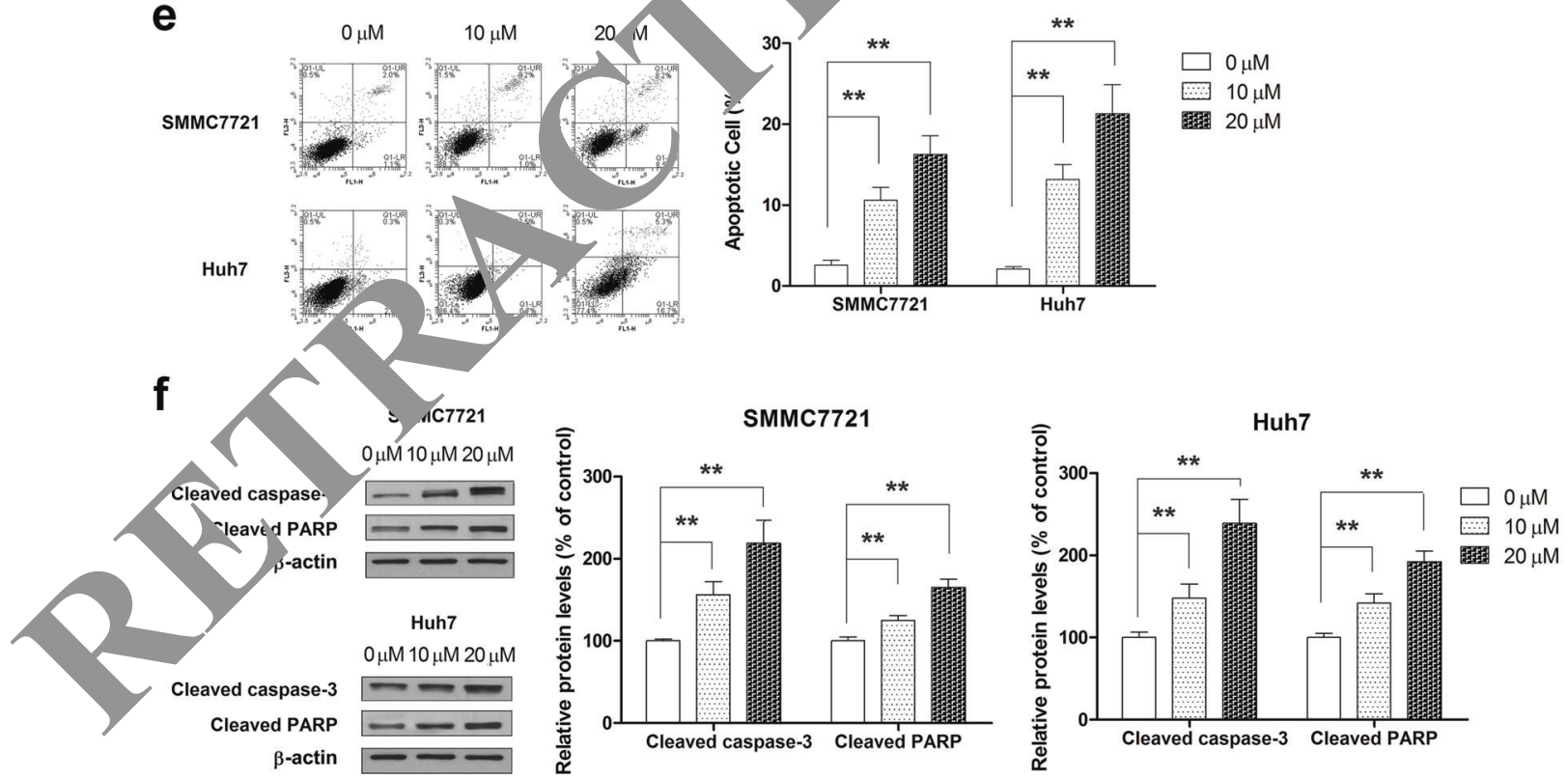

Fig. 1 Hispidulin promotes cell death in HCC cells. a Cell viability of SMMC7721 and Huh7 cells was measured using a CCK-8 assay after hispidulin $(10$ and $20 \mu \mathrm{M})$ treatment for 24 or $48 \mathrm{~h}$. b Colony formation assay of SMMC7721 and Huh7 cells after hispidulin treatment at dosages of 10 and $20 \mu \mathrm{M}$. c Cell morphology was observed under an inverted phase contrast microscope after SMMC7721 and Huh7 cell exposure to hispidulin at dosages of 10 and $20 \mu \mathrm{M}$ for $48 \mathrm{~h}$. d Hoechst 33258 staining analysis of the apoptotic cell population after SMMC7721 and Huh7 cells were exposed to hispidulin at doses of 10 and $20 \mu \mathrm{M}$ for $48 \mathrm{~h}$. Apoptotic cells were observed under a fluorescence microscope (excitation wavelength: $488 \mathrm{~nm}$ ). e SMMC7721 and Huh7 cells were treated with hispidulin (10 and $20 \mu \mathrm{M})$ for $48 \mathrm{~h}$, and flow cytometry was used to quantify the apoptotic cells. f Immunoblot analysis of cleaved caspase-3 and cleaved PARP in SMMC7721 and Huh7 cells after exposure to hispidulin 10 and $20 \mu \mathrm{M}$ for $48 \mathrm{~h}$. ${ }^{* *} P<0.01$ 
a

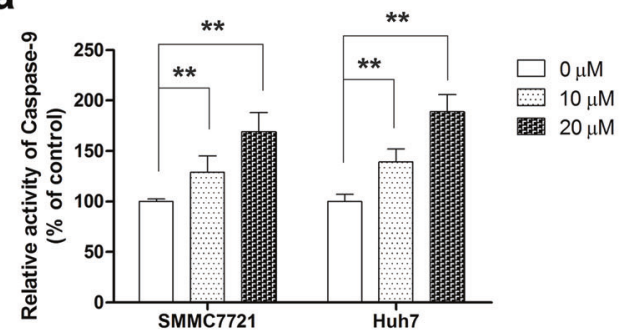

b
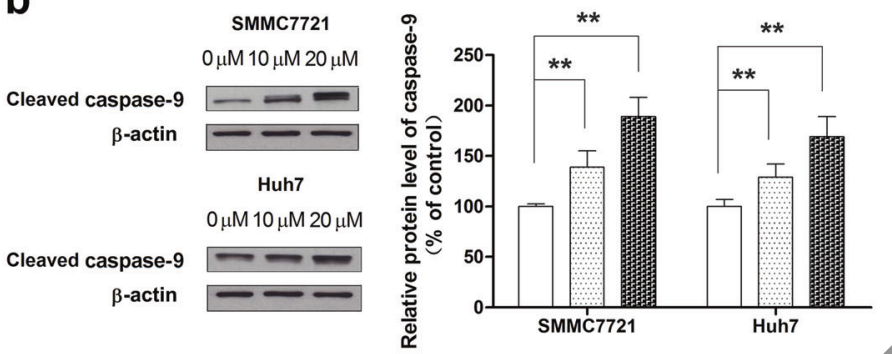

0

$\square 10 \mu \mathrm{M}$

閳䀅 $20 \mu \mathrm{M}$

C
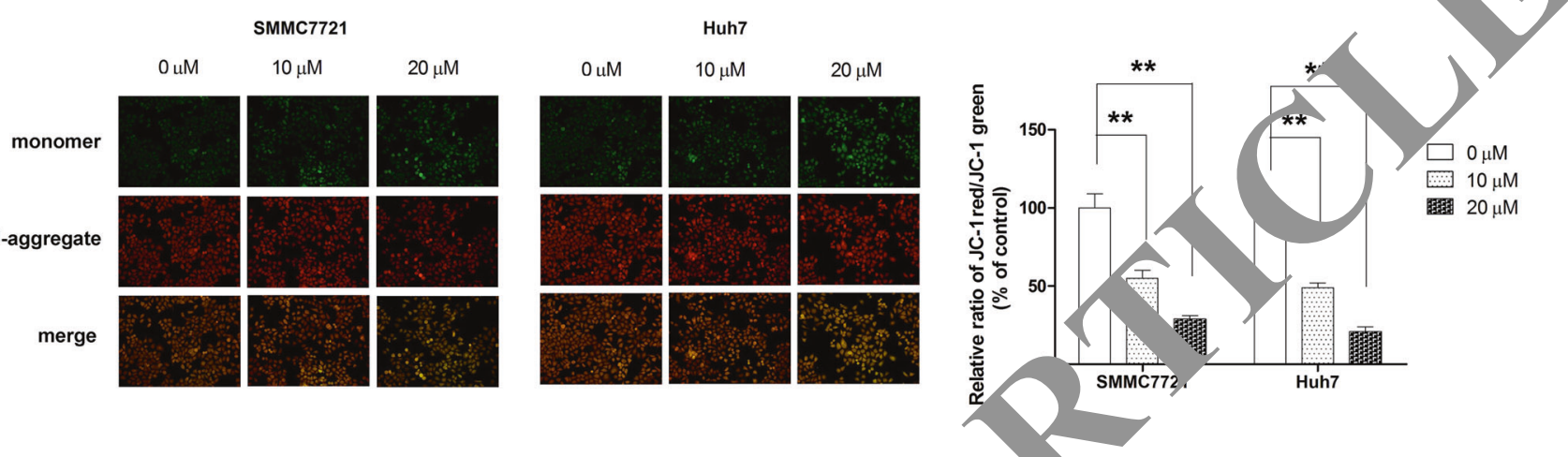

d
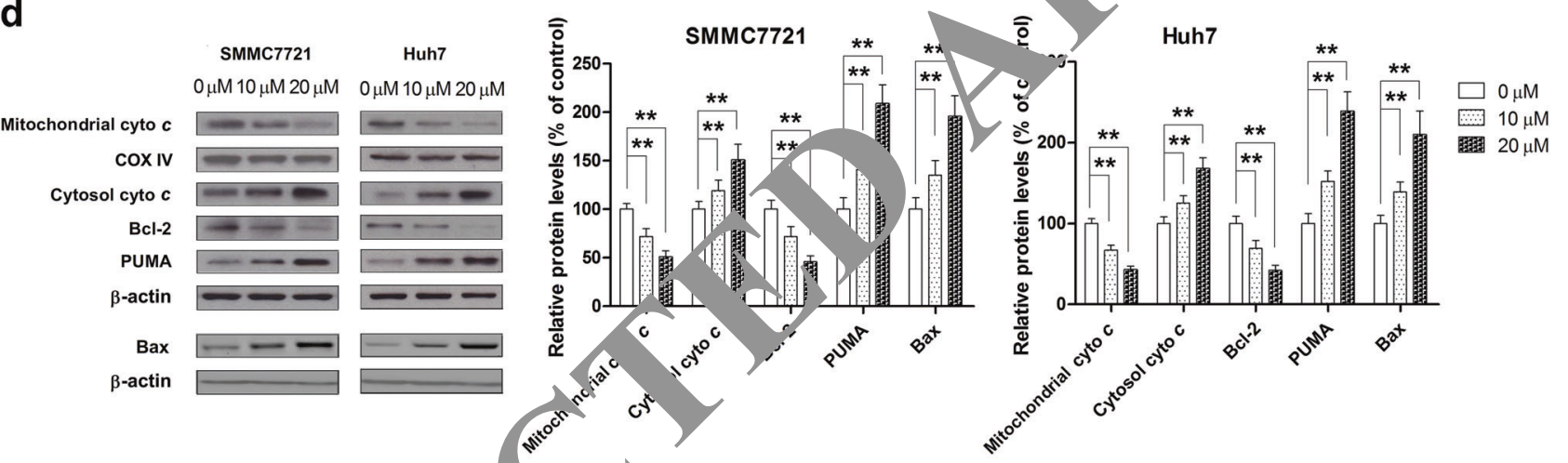

e
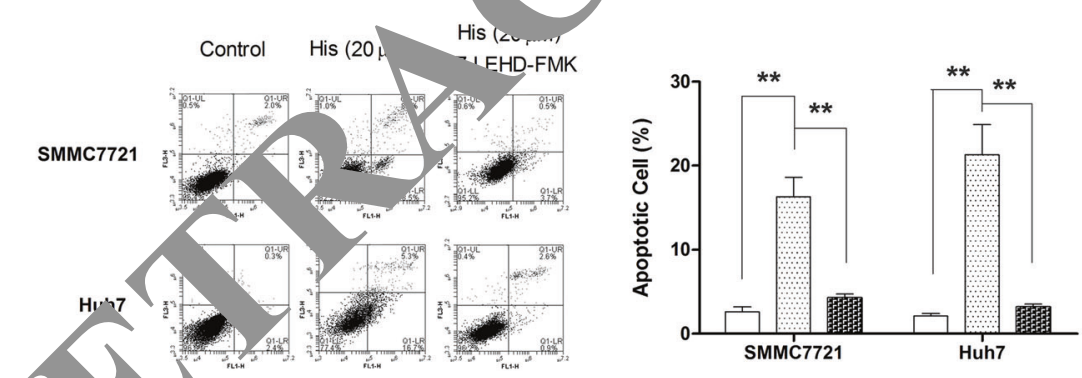

Fig. 2 Hisniduli tiva es the intrinsic mitochondrial apoptotic pathway in HCC cells. a SMMC7721 and Huh7 cells were treated with hispidulin and . M) for $48 \mathrm{~h}$, and the activity of caspase-9 was measured using a caspase-9 ELISA kit. b SMMC7721 and Huh7 cells were treate with aispiduin $(10$ and $20 \mu \mathrm{M})$ for $48 \mathrm{~h}$ and analyzed for protein expression of cleaved caspase-9 by immunoblotting. c SMMC7721 and Huh7 7 . ncubated with hispidulin $(10 \mu \mathrm{M}$ and $20 \mu \mathrm{M})$ for $48 \mathrm{~h}$, and JC-1 staining was performed to detect the changes in the mitochor al membrane potential (MMP). d SMMC7721 and Huh7 cells were treated with hispidulin (10 and $20 \mu \mathrm{M})$ for $48 \mathrm{~h}$, and immunoblot analysis was performed to analyze the protein expression of mitochondrial cyto C, cytosolic cyto C, Bcl-2, Bax, and PUMA. COX-IV and $\beta$-actin were used as loading controls. e SMMC7721 and Huh7 cells were pretreated with caspase-9 inhibitor Z-LEHD-FMK for $6 \mathrm{~h}$, incubated with hispidulin $(20 \mu \mathrm{M})$ for $48 \mathrm{~h}$ and analyzed by flow cytometry to quantify the apoptotic cells ratio. ${ }^{* *} P<0.01$

\section{RESULTS}

Hispidulin effectively suppresses cell growth and promotes apoptosis

To investigate the effect of hispidulin on cell proliferation, we performed CCK-8 assays to evaluate the cell viability of SMMC7721 and Huh7 cells in response to hispidulin. Hispidulin effectively reduced the cell viability in a dose- and time-dependent manner, relative to controls (Fig. 1a). We also examined the effect of hispidulin on the clone-forming ability of HCC cells. Hispidulin treatment caused a significant and dose-dependent decrease in the colony formation ability of SMMC7721 and Huh7 cells (Fig. 1b). Furthermore, microscopic images (Fig. 1c) indicated that 


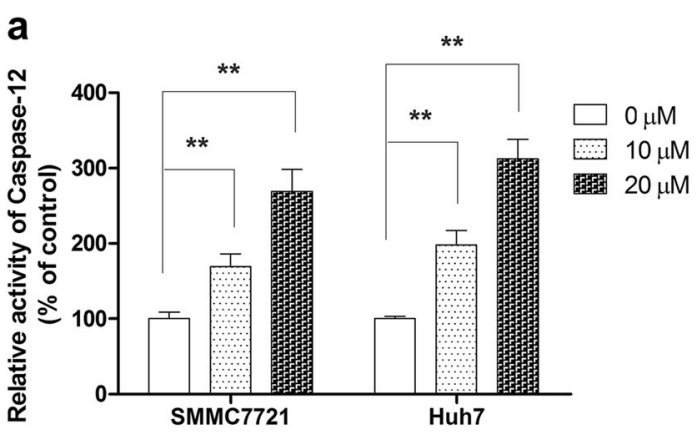

b

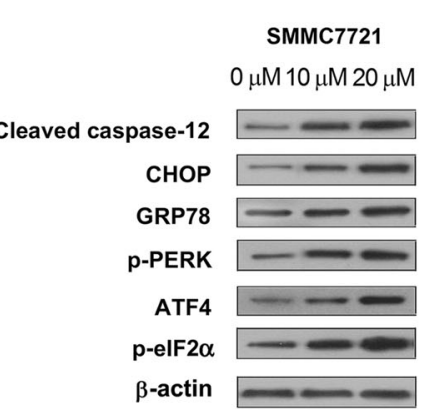

Huh7

$0 \mu \mathrm{M} 10 \mu \mathrm{M} 20 \mu \mathrm{M}$
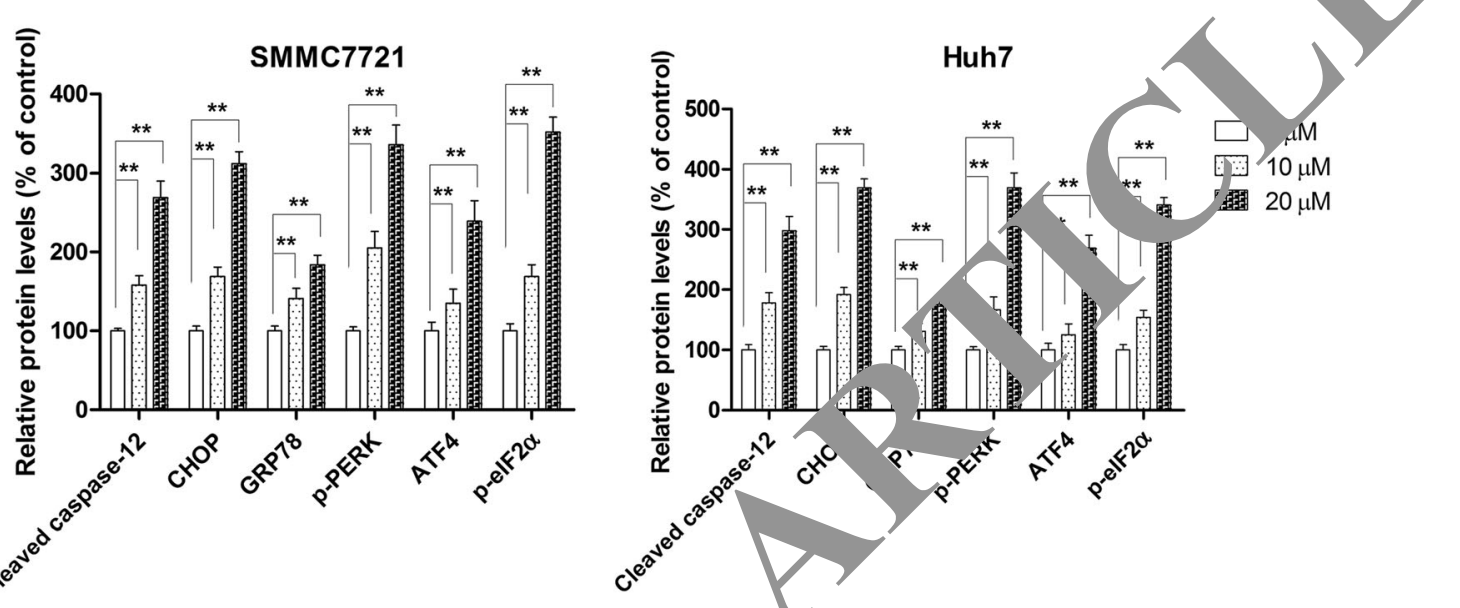

Fig. 3 The pro-apoptotic effect of hispidulin in HCC cells is mediated b; treated with hispidulin $(10$ and $20 \mu \mathrm{M})$ for $48 \mathrm{~h}$, and the activity of analysis shows the expression of ERS-related proteins, including cle

hispidulin exposure significantly increased the number of ang cells and reduced the rate of cellular attachmen relative controls. To test whether apoptosis is the primar (a tributor,$t$ the growth inhibitory effect of hispidulin, Heechst 58 and Annexin V/PI staining were used to identif, apoptosis. vechst 33258 and Annexin V/PI staining results co firmed that hispidulin at $10 \mu \mathrm{M}$ and $20 \mu \mathrm{M}$ dosages significantly creased the percentage of apoptotic cells (Fig. 1d, e) $(P<0.0 \quad$ chermore, we found that hispidulin effectively ased the cleavage of caspase-3 and PARP in SMMC7721 ar a ah7 cells (Fig. 1f). Overall, these results indicate hat th growth inhibitory effects of hispidulin on HCC cells re $m$ diatec toy apoptosis.

Hispidulin induces ce apopto in SMMC7721 and Huh7 cells via the intrinsic pathy $a$,

Our previous stuay ide, ied that intrinsic pathways are involved in the pro-apopiotic efte of hispidulin in HCC cells [30]. To confirm $y$ the hispidulin triggered cell apoptosis through intrinsic pat. vs, ve first examined the activity and protein expres. of Jase-9 in SMMC7721 and Huh7 cells after ex cure on hispidulin $(10 \mu \mathrm{M}$ and $20 \mu \mathrm{M})$. The results indicated that ruum. Increased the activity and cleavage of caspase- 9 in a dose nendent manner (Fig. $2 \mathrm{a}, \mathrm{b})(P<0.01)$. In addition, we examines whether hispidulin treatment affected the MMP, which plays a pivotal role in triggering apoptosis. As shown in Fig. 2c, hispidulin treatment caused a disruption of MMP. Moreover, hispidulin significantly increased the expression of cytosolic cytochrome C, PUMA, and Bax and decreased mitochondrial cytochrome $\mathrm{C}$ and $\mathrm{Bcl}-2$ expression (Fig. $2 \mathrm{~d}$ ). From these results, we can confirm that hispidulin triggers apoptosis via the intrinsic mitochondrial pathway of apoptosis $(P<0.01)$. We further confirmed these findings by demonstrating that pretreatment with a caspase-9 inhibitor (Z-LEHD-FMK) for $6 \mathrm{~h}$ significantly
Inhibited the pro-apoptotic effect of hispidulin on HCC cells (Fig. 2e) $(P<0.01)$. Taken together, these results suggest that hispidulin-induced apoptosis of SMMC7721 and Huh7 cells via intrinsic pathways.

Hispidulin induces ER stress and the UPR pathway

To confirm whether hispidulin treatment activates ERS in HCC cells, we analyzed the activity and expression of ERS-related proteins in response to hispidulin. Hispidulin significantly elevated the activity of caspase-12, which plays a crucial role in cell apoptosis mediated by the ERS signaling pathway (Fig. 3a) $(P<0.01)$. UPR is activated in response to ER stress. Upon UPR activation, the UPR sensor PERK dissociates from GRP78, which promotes PERK oligomerization and autophosphorylation. PERK then phosphorylates the translation initiation factor elF2a (eukaryotic initiation factor $2 a$ ), which triggers the activation of the transcription factor ATF4. ATF4 induces the expression of proteins involved in cell apoptosis, including CHOP and caspase-12 [34]. The expression of ER stress marker GRP78 was significantly elevated in the hispidulin $(10$ and $20 \mu \mathrm{M})$ treatment group relative to the control group $(P<0.01)$. Moreover, the phosphorylation of PERK and elF $2 a$ and the expression of ATF4, CHOP, and cleaved caspase-12 were markedly increased in a dose-dependent manner in hispidulin-treated cells compared with controls (Fig. 3b) $(P<0.01)$. Together, these results show that hispidulin-induced ERS in SMMC7721 and Huh7 cells at least partly via the PERK sensor and its downstream pathways.

Hispidulin exhibits pro-apoptotic effects mainly through the activation of ERS and downstream signaling pathway

To confirm whether hispidulin-induced SMMC7721 and Huh7 cell apoptosis through the ERS-related apoptotic pathway, the 
a

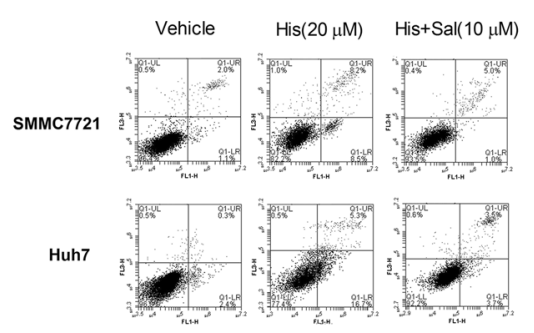

b
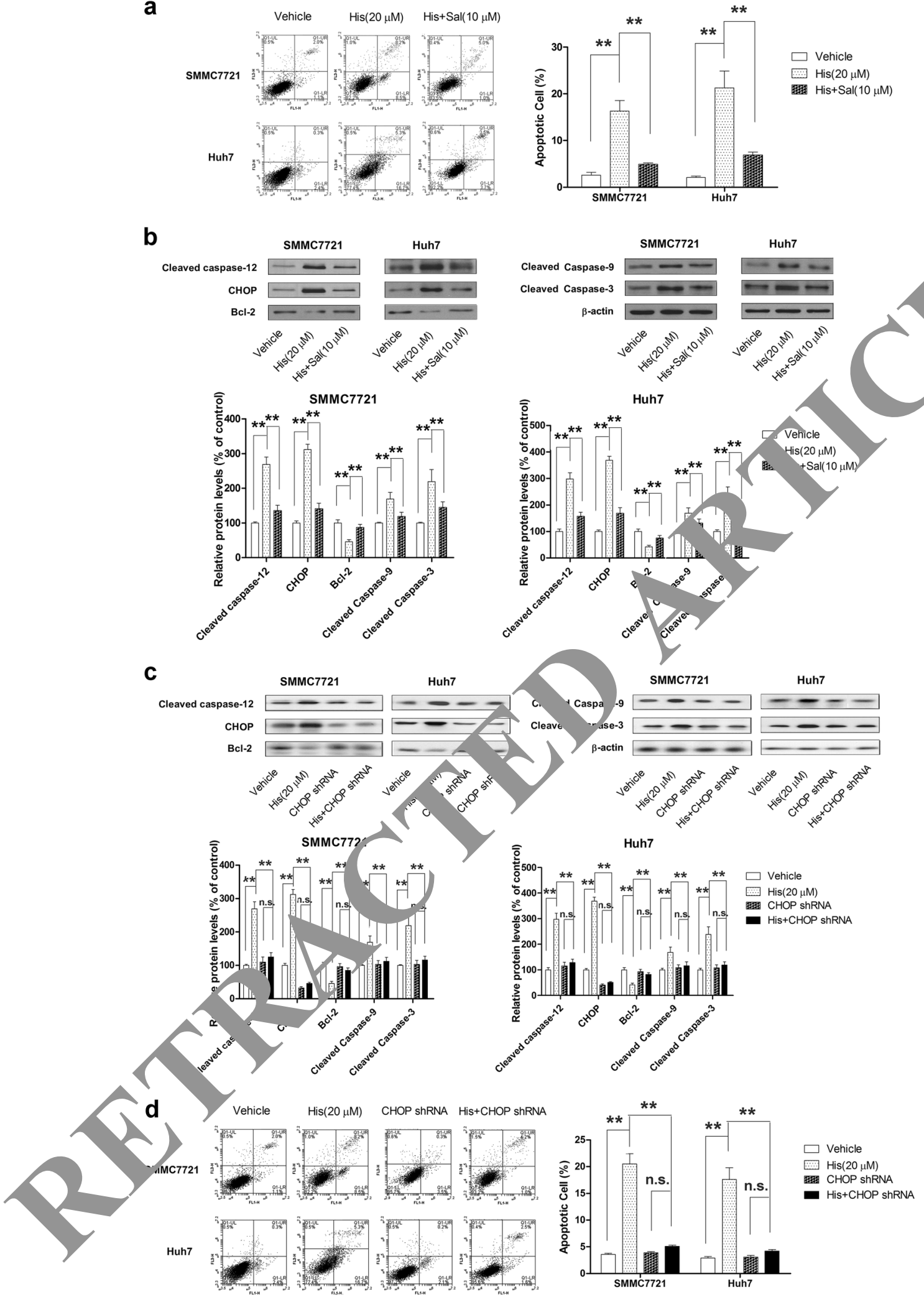

Fig. 4 Blocking the ERS signaling pathway reverses hispidulin-induced apoptosis in HCC cells. a SMMC7721 and Huh7 cells were pretreated with elF $2 \alpha$ selective dephosphorylation inhibitor (Sal $10 \mu \mathrm{M})$ for $6 \mathrm{~h}$ and incubated with hispidulin $(20 \mu \mathrm{M})$ for $48 \mathrm{~h}$, and then, the apoptotic cell ratio was measured by flow cytometry. b SMMC7721 and Huh7 cells were pretreated with ERS inhibitor (Sal) for $6 \mathrm{~h}$ and then incubated with hispidulin $(20 \mu \mathrm{M})$ for $48 \mathrm{~h}$, and immunoblot analysis of the expression of cleaved caspase-12, CHOP, Bcl-2, cleaved caspase-9, and cleaved caspase-3 in HCC cells was performed. c Immunoblot analysis of cleaved caspase-12, CHOP, Bcl-2, cleaved caspase-9, and cleaved caspase-3 in HCC or CHOP shRNA transfection HCC cells after exposure to hispidulin $(20 \mu \mathrm{M})$ for $48 \mathrm{~h}$. d Flow cytometry analysis of apoptotic cells in SMMC7721 and Huh7 cells or CHOP shRNA transfection cells after treatment with hispidulin $(20 \mu M)$. ${ }^{* * P}<0.01$; n.s. not significant 
a
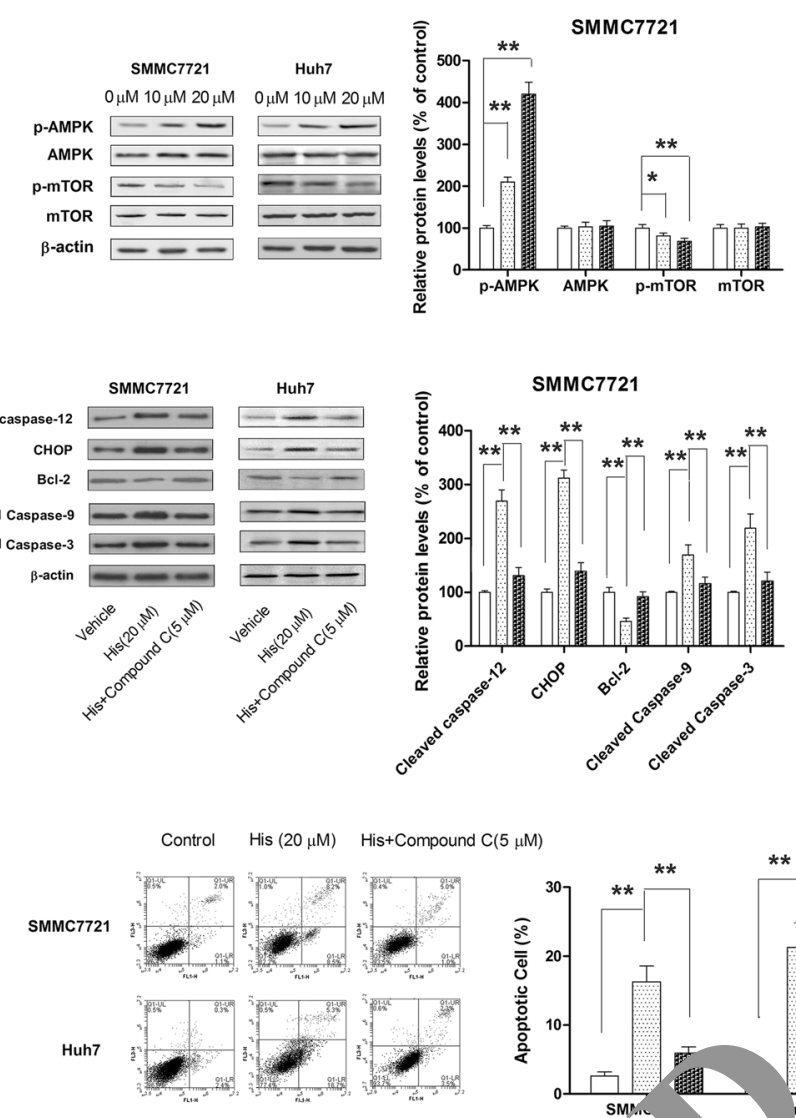

b

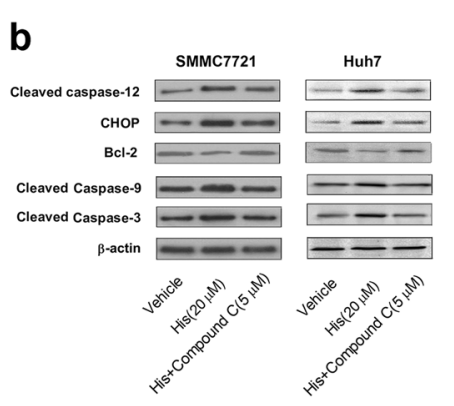

C

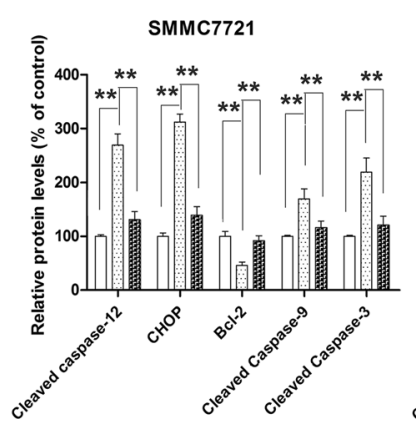

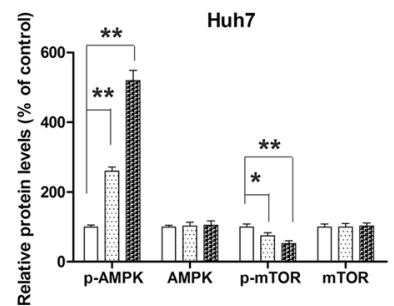

$\square 0 \mu \mathrm{M}$

蔇 $20 \mu \mathrm{M}$

\section{.}

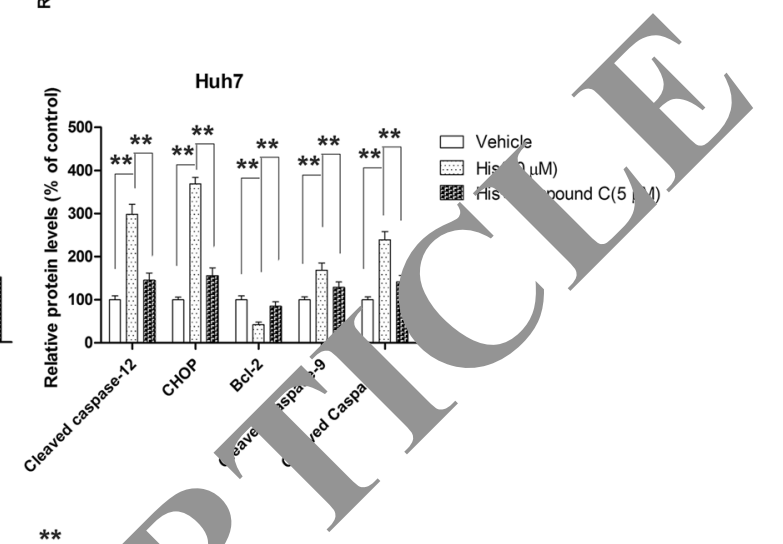

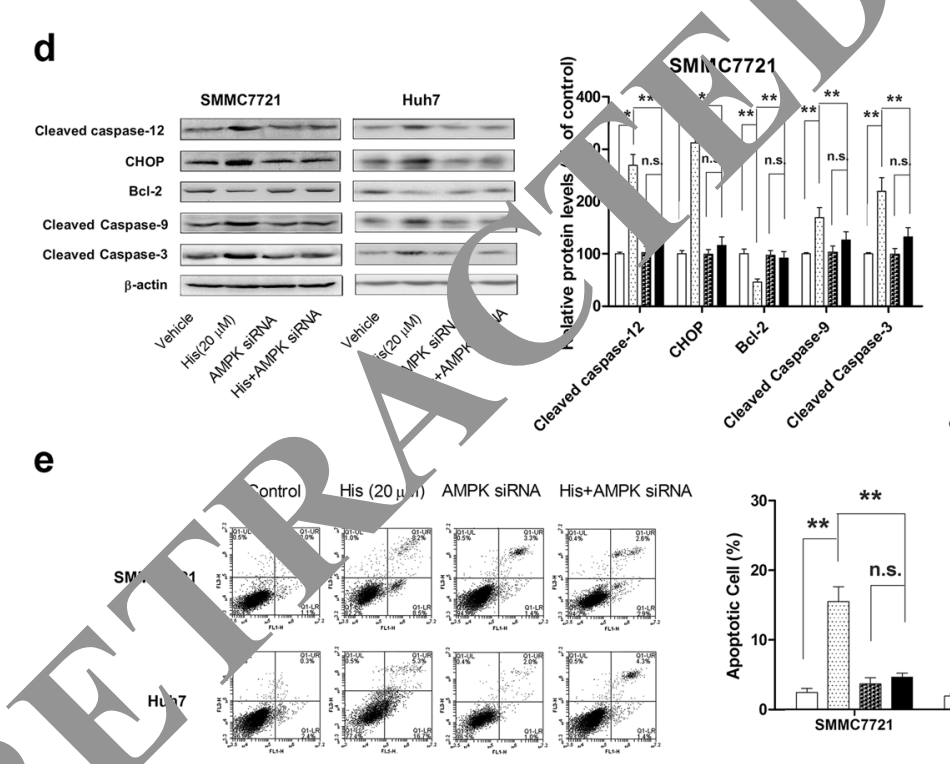
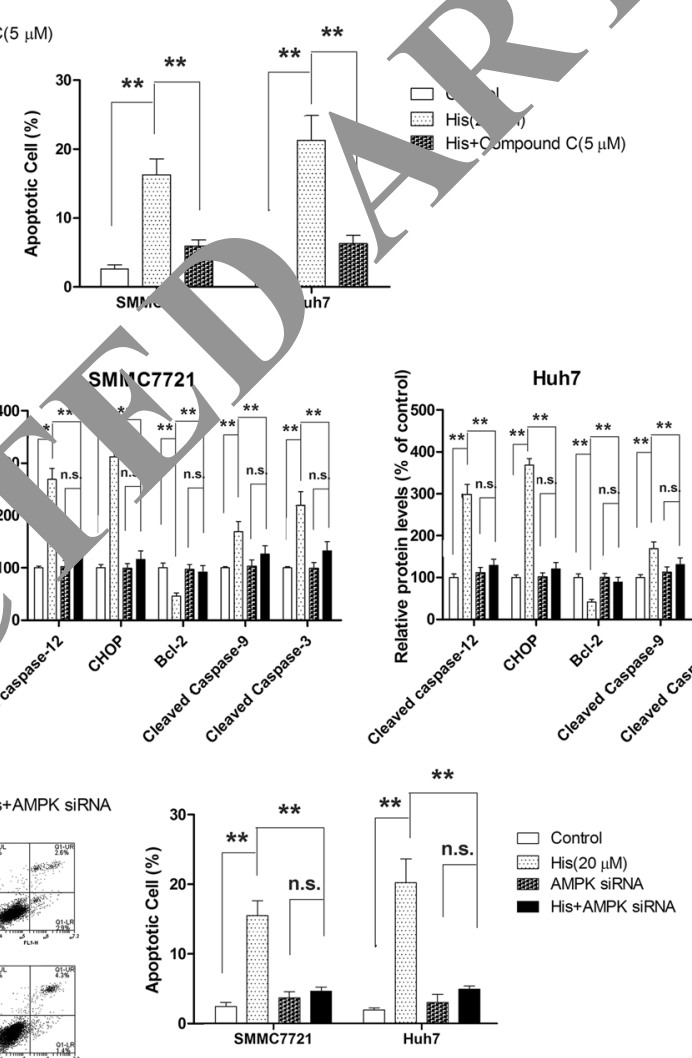

Fia $-\mathrm{H}$. bidulin triggers ERS-related apoptosis through the activation of the AMPK/mTOR pathway. a Immunoblot analysis of the pho 1 level and total protein expression of AMPK and mTOR in SMMC7721 and Huh7 cells after treatment with hispidulin (10 and $20 \mu \mathrm{M}$, $48 \mathrm{~h}$. b SMMC7721 and Huh7 cells were pretreated with AMPK inhibitor Compound C (5 $\mu \mathrm{M})$ for $6 \mathrm{~h}$ and then incubated with hispidulin $(20 \mu \mathrm{M})$ ty $48 \mathrm{~h}$. Immunoblot analysis of the expression of cleaved caspase-12, CHOP, Bcl-2, cleaved caspase-9, and cleaved caspase-3. c Flow cytometry analysis of apoptotic cells in SMMC7721 and Huh7 cells after pretreatment with AMPK inhibitor Compound C (5 $\mu$ M) for $6 \mathrm{~h}$ and incubation with hispidulin $(20 \mu \mathrm{M})$ for $48 \mathrm{~h}$. d Immunoblot analysis of cleaved caspase-12, CHOP, Bcl-2, cleaved caspase-9, and cleaved caspase-3 in AMPK siRNA-transfected SMMC7721 and Huh7 cells after treatment with hispidulin $(20 \mu \mathrm{M})$ for $48 \mathrm{~h}$. e Flow cytometry analysis of apoptotic cells in AMPK siRNA-transfected SMMC7721 and Huh7 cells after treatment with hispidulin $(20 \mu \mathrm{M})$ for 48 h. ${ }^{*} P<0.05$. ${ }^{*} P<0.01$; n.s. not significant

apoptotic cell population and related protein expression were analyzed in the presence of salubrinal (Sal/10 $\mu \mathrm{M})$, a selective inhibitor of elF2a dephosphorylation. Hispidulin $(20 \mu \mathrm{M})$ induced HCC cell apoptosis, and pretreatment of cells with Sal for $6 \mathrm{~h}$ significantly abrogated this effect (Fig. 4a). In addition, Sal reversed the hispidulin-induced increase in the levels of cleaved caspase-12, CHOP, cleaved caspase-9, and cleaved caspase-3 and decrease in the expression of anti-apoptotic protein Bcl-2 (Fig. 4b). 
To further identify the role of ERS in hispidulin-induced apoptosis in HCC cells, a shRNA strategy was applied to stably knockdown CHOP. CHOP shRNA effectively downregulated the expression of CHOP in HCC cells (Fig. 4c). We found that hispidulin-induced apoptosis (Fig. 4d) and changes in protein expression (Fig. 4c) were attenuated in CHOP-silenced HCC cells. These findings confirmed that ER stress activation mediated the pro-apoptotic effects of hispidulin in HCC cells.

Hispidulin-induced apoptosis is mediated by activation of the AMPK signaling pathway

Several studies have demonstrated that the AMPK pathway is implicated in ERS-related cell apoptosis [35]. In line with these findings, our results showed that hispidulin treatment increased phosphorylation of AMPK and decreased the phosphorylation level of mTOR in HCC cells in a dose-dependent manner. Total AMPK and mTOR were used as pan controls (Fig. 5a). We next used AMPK inhibitor Compound $C(5 \mu \mathrm{M})$ or AMPK siRNA to block the AMPK pathway and examine the effects of hispidulin on apoptosis and the expression of related proteins. Pretreatment with AMPK inhibitor Compound C significantly attenuated hispidulin-induced apoptosis and abolished the effects of hispidulin on the expression of related proteins, including cleaved caspase-12, CHOP, Bcl-2, cleaved caspase-9, and cleaved caspase-3. No significant changes were observed when cells were treated with Compound $C$ alone (data not shown) (Fig. 5b, c). Consistent with these findings, AMPK siRNA also significantly abolished the pro-apoptotic effects of hispidulin (Fig. 5d, e). These results collectively demonstrated that hispidulin exerts pro-apoptotic functions via the AMPK/mTOR signaling pathway.

Hispidulin induces ERS-related apoptosis in vivo

On the basis of our in vitro results, an HCC xenograft morse model was used to test the in vivo therapeutic effec of hispidulin. Dosages of hispidulin used were $25 \mathrm{mg} / \mathrm{kg} /$ /ay

$50 \mathrm{mg} / \mathrm{kg} /$ day. Hispidulin significantly suppressed tum or grow at both doses relative to the vehicle group $(P<0 s \mathrm{~s}$,ig. 6a); however, $25 \mathrm{mg} / \mathrm{kg} /$ day and $50 \mathrm{mg} / \mathrm{kg} /$ day hispiaulin not significantly affect the body weight of mice compared wit the vehicle group $(P>0.05)$. Moreover, in an nals treated with hispidulin, a significant increase in TUNL positive cells in tumor issues was observed (Fig. 6b), which the proapoptotic effect of hispidulin. We also mined the expression of CHOP, BCl-2, cleaved caspase-3, a $\mathrm{k}$-67 in tumor tissues using immunohistoche try. In line with our in vitro findings, the results sho ed hat $r$ spidulin significantly upregulated the exprescion and cleaved caspase-3 while downregulating the lev of $\mathrm{BCl}-2$ and $\mathrm{Ki}-67$ (Fig. 6c). Furthermore, hispidy ffectively increased the protein expression of CHOP, GRP78, clea caspase-3, and cleaved caspase-12 and decreased ine express 1 of $\mathrm{Bcl}-2$ in tumor tissues (Fig. $6 \mathrm{~d}$ ). These resul co firmed that hispidulin-induced ERS and apoptosis in vi

DISCU

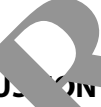

Compare vith conventional chemotherapeutic drugs, natural compounds may exert potent anti-tumor effects without causing many adverse effects. Therefore, the anti-tumor activity of a number of bioactive chemical structures from natural sources has been studied. Hispidulin is a flavonoid compound, and its anti-neoplastic activity has been documented [21, 22, 36]. The role of hispidulin as a chemopreventive agent was first reported in 1992 [37]. In 2010, Way et al. reported that hispidulin-induced apoptosis in ovarian cancer and glioblastoma multiforme cells in vitro $[22,38]$. The pro-apoptotic effect of hispidulin has also been evidenced in hepatoma cells by different groups [29, 39].
Moreover, our previous studies also showed that hispidulin suppressed cell growth and induced apoptosis in vitro and in vivo in clear cell renal cell carcinoma and gallbladder cancer. In the present study, our results showed that hispidulin caused the induction of apoptosis and a reduction in cell viability in HCC cells. Mechanistically, hispidulin-induced ER stress and UPR by activating the AMPK pathway, leading to intrinsic apoptosis in HCC cells.

The ER is a eukaryotic organelle that is responsible for regulating calcium homeostasis, lipid biosynthesis, protrin synthesis, folding, and quality control [40]. ERS, which is triggered by numerous environmental, physiological, and patho. ic: ins Its that disrupt the protein folding environment in the lead to protein misfolding and accumulation [41]. The role of En in the development and progression of cancer is ntrover ial. Endoplasmic reticulum stress generally plays a prote ro in tumor development by activating the adapti e stress res, unse elements and attenuating the apoptotic pathy vs. Accurnulating evidence demonstrated that ERS is li ed tum or initiation [42], quiescence and aggressiveness 27 , eprrielial-to-mesenchymal transition (EMT) [44], angic renesis, metabolic processes [45]. Furthermore, clinical evia a and in vitro studies suggested a strong link between ERS and q resistance. Various studies have shown that GRP78 ects aga ist drug-induced apoptosis [46]. In contrast, sor 5 st dies have shown that the therapeutic induction of ERScancer cells. An earl, udy showed that Icariin protects rat H9c2 cells from a +osis by inhibiting ERS signaling [47]. In EC109 cells, the ERS pati woy nvolved in adenosine-induced apoptosis [48]. Moreover, N-1yc downstream-regulated gene 2 (NDRG2) acts as a prov co-facto / to facilitate the PERK branch of UPR- and ERSindu cell apoptosis in human hepatoma SK-Hep-1 and HepG2

olls [ 4 ]. Zhou et al. found that rosoloactone induces apoptosis in 1. ar cervical cancer cells through endoplasmic reticulum stress anc mitochondrial damage [50]. In the present study, our results vealed that hispidulin-induced ER stress and the inhibition of ER stress by a specific inhibitor or by using CHOP shRNA to inhibit UPR significantly attenuated hispidulin-induced apoptosis, suggesting that ER stress induced by hispidulin is an upstream signaling event that triggers mitochondrial apoptosis in HCC cells.

AMPK is an energy sensor involved in regulating energy balance at both cellular and organismal levels [51]. AMPK is activated when it is phosphorylated at Thr172 (P-AMPKa-Thr172) either by the tumor suppressor kinase LKB1 or an alternate pathway involving the $\mathrm{Ca}^{2+}$ /calmodulin-dependent kinase, CAMKK2 [52]. Accumulating evidence suggests that the activation of AMPK signaling may facilitate growth inhibition and cell killing [53]. A number of studies have shown that small molecules and compounds induce ER stress, leading to apoptosis mainly through the activation of the CaMKK $\beta$-AMPK-mTOR signaling pathway [54]. For instance, thapsigargin causes ERS and sensitizes human esophageal cancer to TRAIL-induced apoptosis via AMPK activation [55]. Our previous studies indicated that hispidulin exhibits anti-cancer activity by activating the AMPK signaling pathway in a variety of tumor cells, including glioblastoma, ovarian cancer cells, colorectal cancer, and hepatocellular carcinoma [21, 22, 27, 28]. However, little is known as to whether hispidulin triggers the ERS pathway through AMPK-mTOR signaling. In this study, hispidulin effectively increased the phosphorylation of AMPK, leading to mTOR inhibition. Treatment of cells with AMPK siRNA or an inhibitor (Compound C) significantly abrogated the effects of hispidulin on CHOP expression and apoptotic-related protein expression, providing evidence that hispidulin triggers ERS by modulating AMPK signaling (Fig. 7).

In summary, our results showed that hispidulin triggers ERSmediated apoptosis by modulating the AMPK/mTOR signaling. These findings suggest that ERS may serve as a potential therapeutic target for the prevention and treatment of cancer. 
a
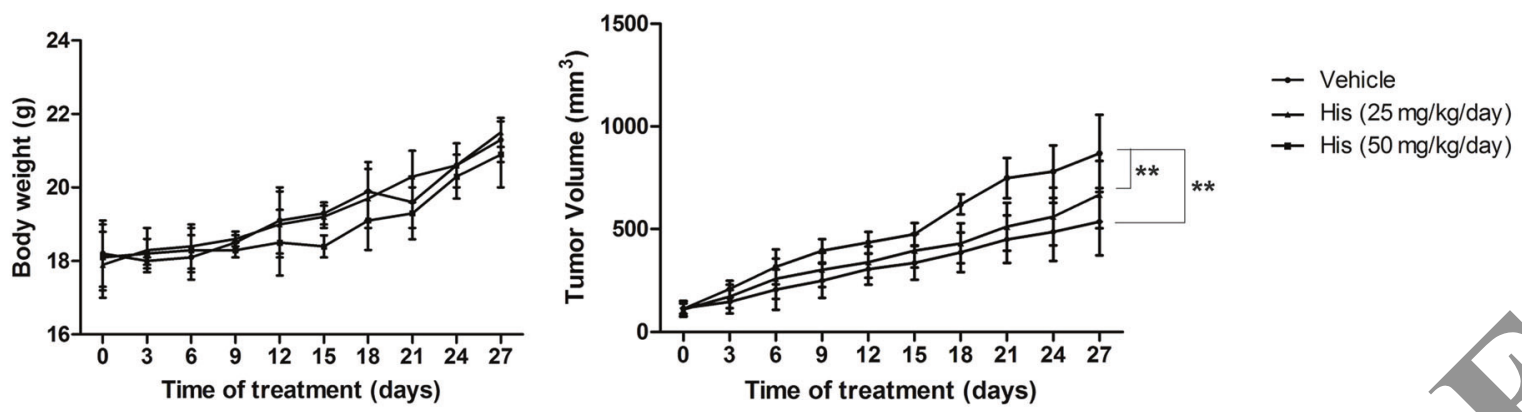

b

Vehicle

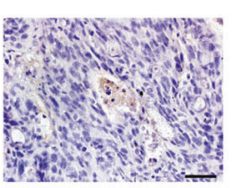

His $(25 \mathrm{mg} / \mathrm{kg} /$ day $) \quad H i s(50 \mathrm{mg} / \mathrm{kg} /$ day $)$

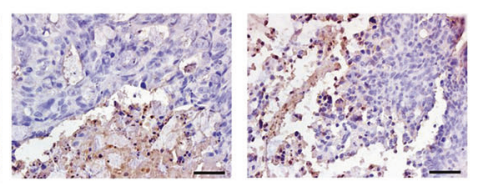

C

Vehicle

His ( $25 \mathrm{mg} / \mathrm{kg} /$ day)

His $(50 \mathrm{mg} / \mathrm{kg} / \mathrm{day})$

CHOP
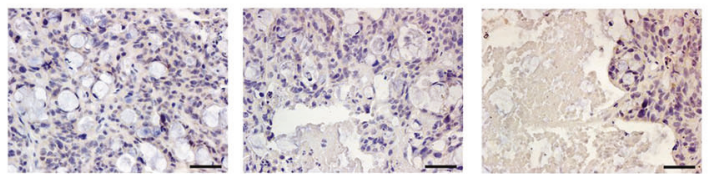

$\mathrm{Bcl}-2$
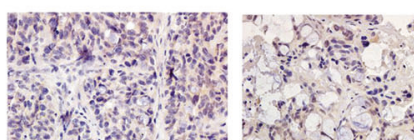

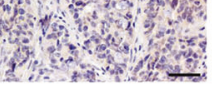

Cleaved

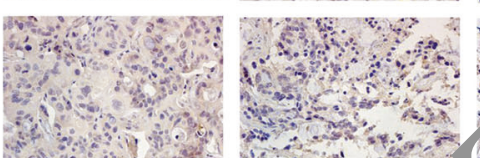

caspase-3
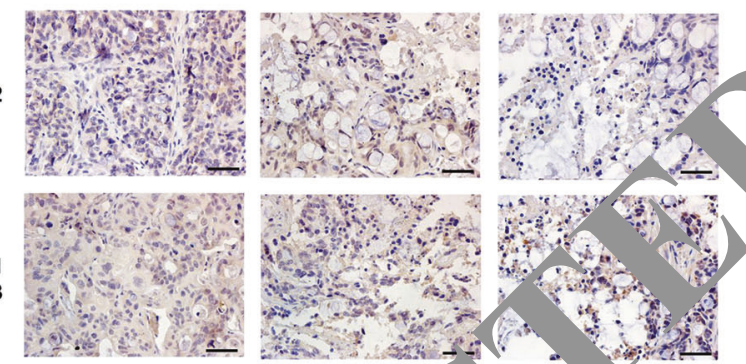

Ki-67
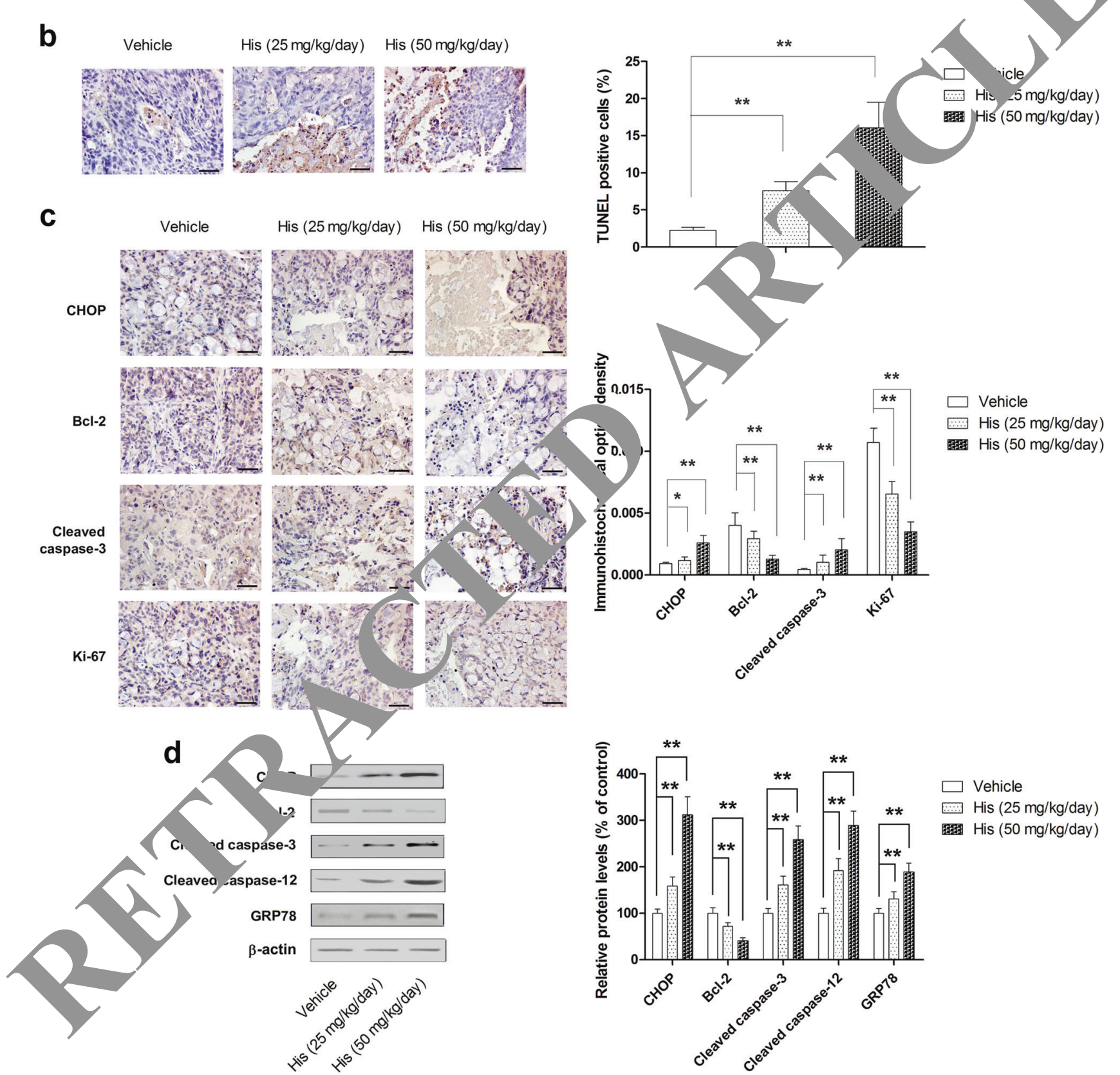

$\square$ Vehicle

5.... His (25 mg/kg/day)

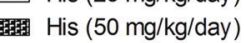

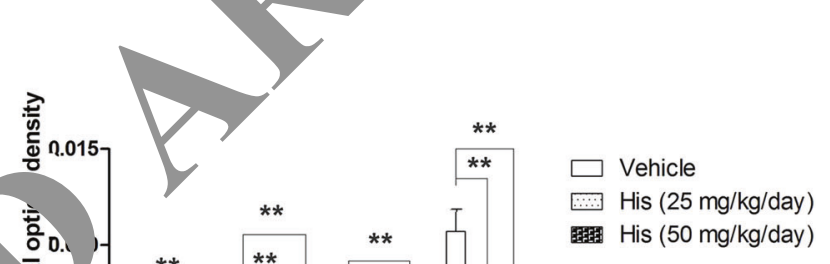

Fig. 6 Hispidulin exhibits anti-tumor activity in vivo through the activation of the ERS signaling pathway, a Measurement of the body weight and tumor volume every 3 days in a HCC xenograft mice model after treatment with different dosages of hispidulin ( 25 and $50 \mathrm{mg} / \mathrm{kg} / \mathrm{day}$ ). b TUNEL assay analysis of apoptotic cell cryostat sections $(4 \mu \mathrm{m}$ sections) of HCC xenograft tumors after treatment with hispidulin. c Immunohistochemistry staining was performed on the cryostat sections ( $4 \mu \mathrm{m}$ sections) of HCC xenograft tumors to detect the expression of CHOP, Bcl-2, cleaved caspase-3, and Ki-67 after treatment with hispidulin. d The protein expression of CHOP, Bcl-2, GRP78, cleaved caspase-3, and cleaved caspase-12 in tumor tissues was detected by immunoblot analysis. Data are presented as the mean \pm SD, $n=8$. ${ }^{*} P<0.05$; ${ }^{* *} P<0.01$ 


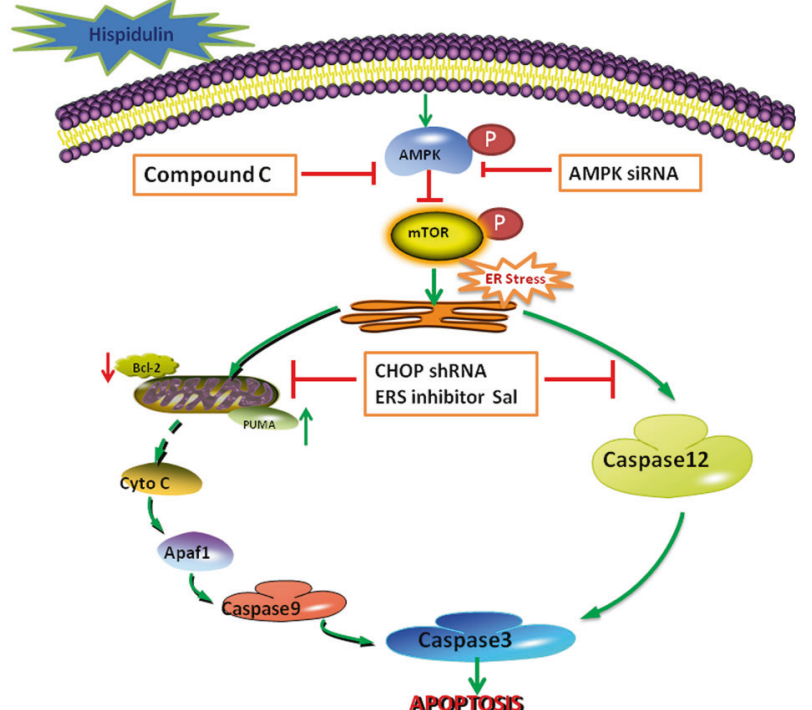

Fig. 7 Schematic model illustrating the potential pathway associated with hispidulin-induced apoptosis in HCC cells

\section{ACKNOWLEDGEMENTS}

This work was supported by the National Natural Science Foundation of China (grant numbers 81603337 and 81274126) and Project of Clinical Medicine $+x$, Medical College, Qingdao University (grant number 2017M38).

\section{AUTHOR CONTRIBUTION}

$\mathrm{MH}, \mathrm{HG}$, and JX designed the study. YPY, QY, MQG, and KLL performed the study. $\mathrm{XHC}$ and $\mathrm{YTH}$ contributed new reagents and analytic tools. ZWH analyzed the data; and $H G$ wrote the paper.

\section{ADDITIONAL INFORMATION}

Competing interests: The authors declare no competing interests

\section{REFERENCES}

1. Jemal A, Bray F, Center MM, Ferlay J, Ward E, Forman Global can ter statistics. CA Cancer J Clin. 2011;61:69-90.

2. Altekruse SF, McGlynn KA, Reichman ME. HE ${ }^{+o c e l l u l a r ~ c u r c i n o m a ~ i n c i d e n c e, ~}$ mortality, and survival trends in the United th 1975 to 2005. J Clin Oncol. 2009;27:1485-91.

3. Ferlay J, Soerjomataram I, Dikshit P, S, Matl ers C, Rebelo M, et al. Cancer incidence and mortality worldy 'e: so ces, me nods and major patterns in GLOBOCAN 2012. Int J Cancer. 20

4. Wang $L$, Yao $M$, Dong $Z$ Lhang $Y, D$, Circulating specific biomarkers in diagnosis of hepatocel'a carcinoma d its metastasis monitoring. Tumour Biol. 2014;35:9-20.

5. Guo Q, Sui Z, Xu Y, Quan X, Su ZX, et al. Ubenimex suppresses Pim-3 kinase expression by targeting CD13 to reverse MDR in HCC cells. Oncotarget. 2017;8:72652-

6. Dong J, 7hai B, S W/, Hu, - Cheng H, Xu J. Activation of phosphatidylinositol 3kinas_A nail sig. ig pathway contributes to epithelial-mesenchymal transit indu $d$ multi drug resistance to sorafenib in hepatocellular carcinoma cells. S Uive. -017;12:e0185088.

7. Zhai B, Jiang X, Xu J, Zhao D, Liu B, et al. Inhibition of Akt reverses the acquired sistance to sorafenib by switching protective autophagy to autophagic cell death in hepatocellular carcinoma. Mol Cancer Ther. 2014;13:1589-98.

8. Lin S, Fujii $M$, Hou DX. Rhein induces apoptosis in $\mathrm{HL}-60$ cells via reactive oxygen species-independent mitochondrial death pathway. Arch Biochem Biophys. 2003;418:99-107.

9. Myoishi M, Hao H, Minamino T, Watanabe K, Nishihira K, Hatakeyama K, et al. Increased endoplasmic reticulum stress in atherosclerotic plaques associated with acute coronary syndrome. Circulation. 2007;116:1226-33.

10. Hetz $C$. The unfolded protein response: controlling cell fate decisions under ER stress and beyond. Nat Rev Mol Cell Biol. 2012;13:89-102.
11. Ding W, Zhang X, Huang H, Ding N, Zhang S, Hutchinson SZ, et al. Adiponectin protects rat myocardium against chronic intermittent hypoxia-induced injury via inhibition of endoplasmic reticulum stress. PLoS ONE. 2014;9:e94545.

12. Harvey A, Edrada-Ebel R, Quinn R. The re-emergence of natural products for drug discovery in the genomics era. Nat Rev Drug Discov. 2015;14:111-29.

13. Xu YJ, Zhao DX, Fu CX, Cheng LQ, Wang NF, Han LJ, et al. Determination of flavonoid compounds from Saussurea involucrata by liquid chromatography electrospray ionisation mass spectrometry. Nat Prod Res. 2009;23:1689-98.

14. Bourdillat B, Delautier D, Labat C, Benveniste J, Potier P, Brink C. Mechanism of action of hispidulin, a natural flavone, on human platelets. Prog Clin Biol Res. 1988;280:211-4.

15. Kavvadias D, Sand P, Youdim KA, Qaiser MZ, Rice-Evans C, Ba Ar R, et al. The flavone hispidulin, a benzodiazepine receptor ligand with itiv allosteric properties, traverses the blood-brain barrier and exhibits anticon ive eff cts. Br J Pharmacol. 2004;142:811-20.

16. Niu X, Chen J, Wang P, Zhou H, Li S, Zhang M. T effects of hisp dulin on bupivacaine-induced neurotoxicity: role of AMPK sign. q path ay. Cell Biochem Biophys. 2014;70:241-9.

17. Tan RX, Lu H, Wolfender JL, Yu TT, Zheng V F, Yang L, et al. vono- and sesquiterpenes and antifungal constituents, fro Artemisia species. Planta Med. 1999;65:64-7.

18. Yin $Y$, Gong FY, Wu XX, Sun $Y$, Li Then , al al. Anti-inflammatory and immunosuppressive effect of $f$ avones is $d$ from Artemisia vestita. J Ethnopharmacol. 2008;120:1-6

19. Zhou R, Wang Z, Ma C. Hisph exerts anti-osteoporotic activity in ovariectomized mice via activating AMi ignaling pathway. Cell Biochem Biophys. 2014;69:311-7.

20. Yu CY, Su KY, Lf Jha Tsan PH, Chan DC, et al. Potential therapeutic role of hispidulin in gas. ancer urough induction of apoptosis via NAG-1 signaling. Evid Based Comp altern Med. 2013;2013:518301.

21. Wang $Y$, He $X$, ei Z. Hispidulin enhances the anti-tumor effects of temozolom de oblastoma by activating AMPK. Cell Biochem Biophys. 2015;71:701-

22 Yang JM, Hun $\mathrm{CM}$, Fu CN, Lee JC, Huang $\mathrm{CH}$, Yang MH, et al. Hispidulin sensitizes 7n ovarian cancer cells to TRAlL-induced apoptosis by AMPK activation lea $g$ to Mcl-1 block in translation. J Agric Food Chem. 2010;58:10020-6. Gao ,, Gao M, Peng J, Han M, Liu K, Han Y. Hispidulin mediates apoptosis in in an renal cell carcinoma by inducing ceramide accumulation. Acta Pharmacol in. 2017;38:1618-31.

Gao M, Gao H, Han M, Liu K, Peng J, Han Y. Hispidulin suppresses tumor growth and metastasis in renal cell carcinoma by modulating ceramide-sphingosine 1phosphate rheostat. Am J Cancer Res. 2017;7:1501-14.

25. Gao H, Liu Y, Li K, Wu T, Peng J, Jing F. Hispidulin induces mitochondrial apoptosis in acute myeloid leukemia cells by targeting extracellular matrix metalloproteinase inducer. Am J Transl Res. 2016;8:1115-32.

26. Gao H, Xie J, Peng J, Han Y, Jiang Q, Han M, et al. Hispidulin inhibits proliferation and enhances chemosensitivity of gallbladder cancer cells by targeting HIF-1a. Exp Cell Res. 2015;332:236-46.

27. Liu K, Gao H, Wang Q, Wang L, Zhang B, Han Z, et al. Hispidulin suppresses cell growth and metastasis by targeting PIM1 through JAK2/STAT3 signaling in colorectal cancer. Cancer Sci. 2018;109:1369-81. https://doi.org/10.1111/ cas. 13575 .

28. Han M, Gao H, Ju P, Gao MQ, Yuan YP, Chen XH, et al. Hispidulin inhibits hepatocellular carcinoma growth and metastasis through AMPK and ERK signaling mediated activation of PPARgamma. Biomed Pharmacother. 2018;103:272-83.

29. Scoparo CT, Valdameri G, Worfel PR, Guterres FA, Martinez GR, Winnischofer SM et al. Dual properties of hispidulin: antiproliferative effects on HepG2 cancer cells and selective inhibition of $A B C G 2$ transport activity. Mol Cell Biochem. 2015;409:123-33.

30. Gao $\mathrm{H}$, Wang $\mathrm{H}$, Peng J. Hispidulin induces apoptosis through mitochondrial dysfunction and inhibition of P13k/Akt signalling pathway in HepG2 cancer cells. Cell Biochem Biophys. 2014;69:27-34.

31. Herrerias T, Oliveira AA, Belem ML, Oliveira BH, Carnieri EGS, Cadena SMSC, et al. Effects of natural flavones on membrane properties and citotoxicity of HeLa cells. Rev Bras De Farmacogn. 2010;20:403-8.

32. Wu K, Li N, Sun H, Xu T, Jin F, Nie J. Endoplasmic reticulum stress activation mediates Ginseng Rg3-induced anti-gallbladder cancer cell activity. Biochem Biophys Res Commun. 2015;466:369-75.

33. Han Y, Yang X, Zhao N, Peng J, Gao H, Qiu X. Alpinumisoflavone induces apoptosis in esophageal squamous cell carcinoma by modulating miR-370/ PIM1 signaling. Am J Cancer Res. 2016;6:2755-71.

34. Avril T, Vauleon E, Chevet E. Endoplasmic reticulum stress signaling and chemotherapy resistance in solid cancers. Oncogenesis. 2017;6:e373. 
35. Zhuo XZ, Wu Y, Ni YJ, Liu JH, Gong M, Wang XH, et al. Isoproterenol instigates cardiomyocyte apoptosis and heart failure via AMPK inactivation-mediated endoplasmic reticulum stress. Apoptosis. 2013;18:800-10.

36. He L, Wu Y, Lin L, Wang J, Chen Y, Yi Z, et al. Hispidulin, a small flavonoid molecule, suppresses the angiogenesis and growth of human pancreatic cancer by targeting vascular endothelial growth factor receptor 2-mediated PI3K/Akt/ mTOR signaling pathway. Cancer Sci. 2011;102:219-25.

37. Liu YL, Ho DK, Cassady JM, Cook VM, Baird WM. Isolation of potential cancer chemopreventive agents from Eriodictyon californicum. J Nat Prod. 1992;55:357-63.

38. Lin YC, Hung CM, Tsai JC, Lee JC, Chen YL, Wei CW, et al. Hispidulin potently inhibits human glioblastoma multiforme cells through activation of AMPactivated protein kinase (AMPK). J Agric Food Chem. 2010;58:9511-7.

39. Wu J, Ru NY, Zhang Y, Li Y, Wei D, Ren Z, et al. HAb18G/CD147 promotes epithelial-mesenchymal transition through TGF-beta signaling and is transcriptionally regulated by Slug. Oncogene. 2011;30:4410-27.

40. Healy SJ, Gorman AM, Mousavi-Shafaei P, Gupta S, Samali A. Targeting the endoplasmic reticulum-stress response as an anticancer strategy. Eur J Pharmacol. 2009;625:234-46.

41. Travers KJ, Patil CK, Wodicka L, Lockhart DJ, Weissman JS, Walter P. Functional and genomic analyses reveal an essential coordination between the unfolded protein response and ER-associated degradation. Cell. 2000;101:249-58.

42. Niederreiter L, Fritz T, Adolph T, Krismer A, Offner F, Tschurtschenthaler M, et al. ER stress transcription factor $\mathrm{Xbp} 1$ suppresses intestinal tumorigenesis and directs intestinal stem cells. J Exp Med. 2013;210:2041-56.

43. Schewe $D$, Aguirre-Ghiso J. ATF6alpha-Rheb-mTOR signaling promotes survival of dormant tumor cells in vivo. Proc Natl Acad Sci USA. 2008;105:10519-24.

44. Li $\mathrm{H}$, Chen X, Gao Y, Wu J, Zeng F, Song F. XBP1 induces snail expression to promote epithelial- to-mesenchymal transition and invasion of breast cancer cells. Cell Signal. 2015;27:82-9.

45. Drogat B, Auguste $P$, Nguyen D, Bouchecareilh M, Pineau R, Nalbantoglu J, et al. IRE1 signaling is essential for ischemia-induced vascular endothelial growth
factor-A expression and contributes to angiogenesis and tumor growth in vivo. Cancer Res. 2007:67:6700-7.

46. Lee E, Nichols P, Spicer D, Groshen S, Yu M, Lee A. GRP78 as a novel predictor of responsiveness to chemotherapy in breast cancer. Cancer Res. 2006;66:7849-53.

47. Zhang $\mathrm{Q}$, Li H, Wang $\mathrm{S}$, Liu $\mathrm{M}$, Feng $\mathrm{Y}$, Wang $\mathrm{X}$. Icariin protects rat cardiac H9c2 cells from apoptosis by inhibiting endoplasmic reticulum stress. Int J Mol Sci. 2013;14:17845-60.

48. Wu L, Wei B, Guo Y, Ye Y, Li G, Pu Z, et al. Apoptosis induced by adenosine involves endoplasmic reticulum stress in EC109 cells. Int J Mol Med. 2012:30:797-804.

49. Zhang $M$, Liu X, Wang $Q$, Ru Y, Xiong $X$, Wu K, et al. NDRG2 acts as a PERK cofactor to facilitate PERK branch and ERS-induced $c \in$ ' 'at FEES Lett. 2017;591:3670-81.

50. Zhou L, Qin J, Ma L, Li H, Li L, Ning C, et al. Rosoloactone: a nat. diterpenoid inducing apoptosis in human cervical cancer cells ugh endoplastric reticulum stress and mitochondrial damage. Biomed Pharmace r. 2017; j:355-62.

51. Hardie DG. AMPK--sensing energy while ta' ing to othe "n-ing pathways. Cell Metab. 2014;20:939-52.

52. Hawley SA, Pan DA, Mustard KJ, Ross L, in J, Edeln an AM, et al. Calmodulindependent protein kinase kinase- $r$ ta is a rnati e upstream kinase for AMPactivated protein kinase. Cell Meta $105 ; 2:, \ldots$.

53. Pradelli LA, Beneteau M, CraUVIn C, , in MA, Marchetti S, Munoz-Pinedo $C$, et al. Glycolysis inhibiti, nsitizes tu. or cells to death receptors-induced apoptosis by AMP $\mathrm{kn}$, ase ation leading to $\mathrm{Mcl}-1$ block in translation. Oncogene. 2010;29.1541-52.

54. Zhao F, Huang sv, L ig Z, Mao L, Han Y, Yan J, et al. Triptolide induces protective autop thr activation of the CaMKKbeta-AMPK signaling pathway in prostate canc गlls. Uimotarget. 2016;7:5366-82.

55. Ma Z, Fan C, Yang di S, Hu W, Li T, et al. Thapsigargin sensitizes human esophá ancer tc TRAlL-induced apoptosis via AMPK activation. Sci Rep. 2016;6:3

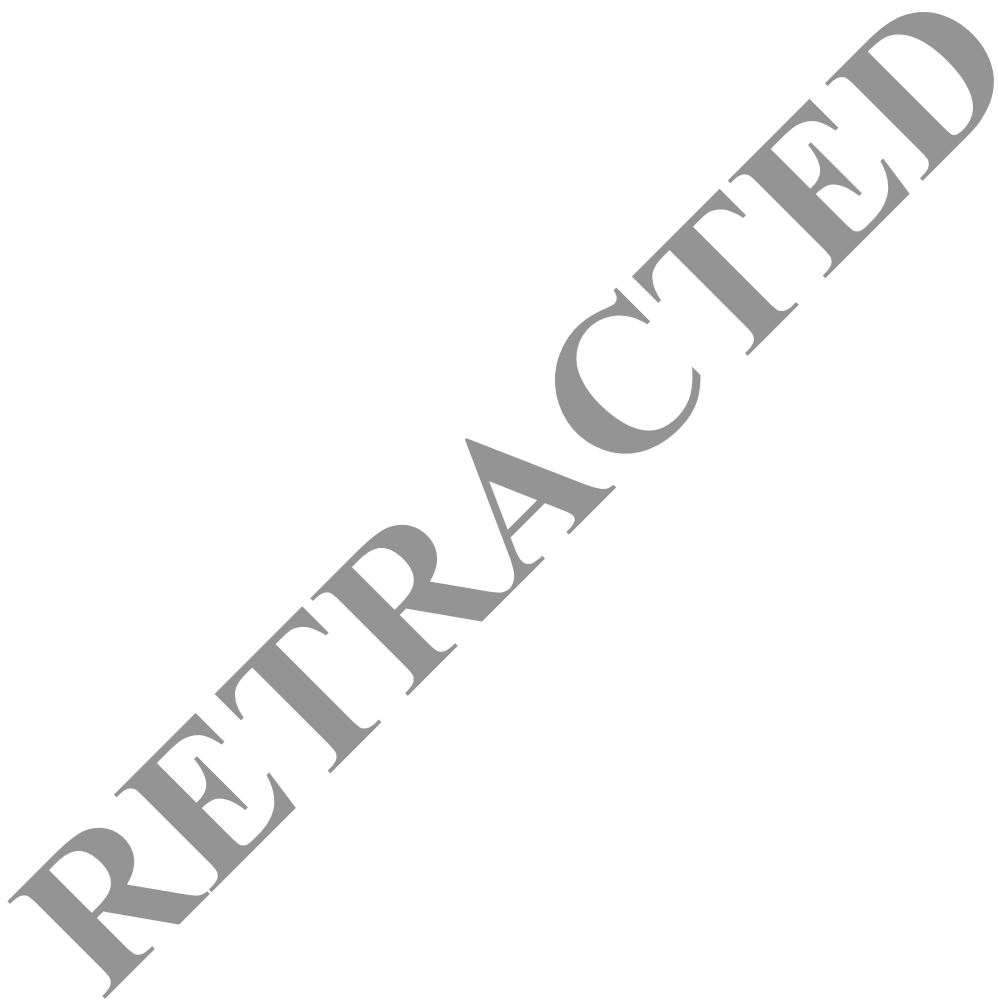

